\title{
Single volar locking plating for the intra- and extra-articular distal radius fractures with dorsal metaphyseal comminution
}

Xue-yang Gui ${ }^{1+}$, Zhao-hui Cheng ${ }^{2+}$, Hong-fei Shi ${ }^{*}$, Yi-xin Chen ${ }^{1}$, Jin Xiong ${ }^{1}$, Jun-fei Wang ${ }^{1}, X$ Zi-tao Zhang ${ }^{1}$

\section{Abstract}

Background: Volar locking plating remains a popular method for the surgical managen t of distal radius fractures. Dorsal metaphyseal comminution (DMC) is a common fracture pattern which ens the stability during fracture fixation. In this study, we aimed to compare the radiographic and functiona the intra- and extra-articular distal radius fractures with DMC following single volar locking plate fixation.

Materials and methods: Patients suffered from a distal radius fracture DMC vere reviewed in the clinical database of the authors' institution between Jan 2016 and Jan 2020. The incluy,ed patients were classified into the extra-articular (A3) group or the intra-articular (C2 and C3) groun accordin a to the AO/OTA system. The radiological parameters, wrist range of motion, and functional outcome we, valuated following open reduction and volar locking plate fixation.

Results: A total of 130 patients were included in thic study wit mean follow-up length of 17.2 months. Compared with the A3 fracture group, no significant fracture re vrace nent or reduced wrist ROMs was observed in the C2 fractures after 12-month's follow-up. However ignifica caecreased volar tilt $(P=0.003)$ as well as the extension/ flexion ROMs were observed in the C3 fract ires amparing to the A3 fractures. Most of the patients achieved an excellent $(n=75)$ or good $(n=51)$ Gart arrd and wey wrist score. Four patients with C3 fractures resulted in a fair functional outcome due to a significa t loss of volar tilt during follow-up.

Conclusions: The single volar locking "ate fix ttion provided sufficient stability for distal radius fractures with DMC, and resulted in similar radiological àd functiond outcomes in the intra-articular distal radius fractures with a simple articular component (C2 fractures) a se in the extra-articular fractures. Considering the intra-articular fractures with multifragmentary articul ompo rent (C3 fracture), despite of the subsequent loss of volar tilt, the majority of the patients achieved go to xceller, wrist function following single volar locking plating.

Trial registratior. This dy has been registered on the ClinicalTrials.gov.

Keywords: d. stal fial fracture, comminution, locking plate, stability, intra-articular fracture

\section{* orresp ndence: nichaelshi@nju.edu.cn}

Id Zhao-hui Cheng contributed equally to this work.

${ }^{2}$ Nan, Drum Tower Hospital Clinical College of Nanjing Medical University,

Nanjing, , Ina

Full list of author information is available at the end of the article

(C) The Author(s). 2021 Open Access This article is licensed under a Creative Commons Attribution 4.0 International License, which permits use, sharing, adaptation, distribution and reproduction in any medium or format, as long as you give appropriate credit to the original author(s) and the source, provide a link to the Creative Commons licence, and indicate if changes were made. The images or other third party material in this article are included in the article's Creative Commons licence, unless indicated otherwise in a credit line to the material. If material is not included in the article's Creative Commons licence and your intended use is not permitted by statutory regulation or exceeds the permitted use, you will need to obtain permission directly from the copyright holder. To view a copy of this licence, visit http://creativecommons.org/licenses/by/4.0/ The Creative Commons Public Domain Dedication waiver (http://creativecommons.org/publicdomain/zero/1.0/) applies to the data made available in this article, unless otherwise stated in a credit line to the data. 


\section{Introduction}

Distal radial fractures are common orthopedic injuries comprising $15 \%$ of all extremity fractures [1]. Though The K-wire pinning and minimally invasive system [2], external fixation [3] and dorsal plating [4] are considered as reasonable fixation options for the distal radial fractures, volar plating remains the most popular fixation techniques because of the safe and straightforward surgical approach, the low rate of complication, and the rapid return to function recovery [5]. Dorsal metaphyseal comminution (DMC) is the most common fracture pattern observed in $60 \%$ of the distal radius fractures [6]. It is well-recognized that DMC weakens the stability of the distal radius and leads to higher rates of secondary displacement when managed conservatively [6-9]. Despite the improved strength characteristics compared with the traditional nonlocking plates, the stability provided by single volar fixed-angled locking plating has also been questioned in this fracture pattern. In vitro, biomechanical studies have testified the stability of volar locking plate in extra-articular distal radius fracture models with DMC, and an equivalent [10] or slightly less stability [4, 11] can be provide compared with dorsal plating. However, the efficacy of single volar locking plating in the intra-articular distal radius fracture with DMC has not yet been adequately analyzed in biomechanical or ical studies. The purpose of the present study analyze the radiographic and functional outconte or intra- and extra-articular distal radius fr $a$ res wit, DMC treated with single volar locking plating.

\section{Materials and methods}

We retrospectively reviewed the patic with distal radius fractures who received ope duction and internal fixation in the authors' institution Ee een Jan 2016 and Jan 2020. The study respus national ethical standards and the Helsinki Con nt The study protocol was approved by our institut. 's Medical Ethics Committee and the informea nsent yas obtained.

Patients yore enro dinto this study according to the following inclusion criteria: 1) the distal radius fracture was fixed n a ingle volar locking plate; 2) DMC was cor $1 \mathrm{n}$ ed he preoperative radiographs and com$P$ d mographic (CT) images according to the definition literature [12]; 3) patients were followed for a minim, m of 1-year postoperatively. Exclusion criteria were: open fractures, delayed fractures, neurovascular injuries, additional ipsilateral upper extremity fractures, or the fractures fixed with additional dorsal or radial plates. The included patients were classified into the extraarticular (A3) group or the intra-articular (C2 and C3) group according to the AO/OTA system [13].

All patients were operated on by two senior attending surgeons (JX and HFS). During operation, the fracture was accessed through the modified volar Henry approach. Briefly, the skin was incised along the course of the flexor carpi radialis (FCR) tendon. The sheath of the FCR was opened and the FCR tendon and the flexor pollicis longus tendon were retracted ulnarly. The radial artery was carefully protected. The pronator quadratus was incised longitudinally and elevated to expose the distal radius. For extra-articular fractures, a plied longitudinal traction and reduced the fracture un ect visualization. For intra-articular fr $r$ ures, eith $\mu_{2}$ the radial column or the palmoulnar frome coul $\alpha$ be reduced firstly to provide reference for the dial height and radial inclination. Dorsal ul $r$ fragments were then reduced to restore joint co ruen and volar tilt. The joy-stick technique with percu eous pinning from the dorsal side was used cilitate eduction of the dorsal fragment if necessary [14, In case the dorsal fragment could not be ad -qu ely redi,ced percutaneously, an additional dorsal isi immediately ulnar to the Lister tubercle was pert ned to facilitate fracture reduction. Followin n cision of the extensor retinaculum and mobilization 0 . the extensor pollicis longus tendon (EPL), the third and the fourth extensor compartment Wa pened. The dorsal fracture fragment was then reduce under direct visualization. After temporary K-wire tion, a satisfactory reduction of the extra- and intraarticular fracture was checked using intraoperative Carm according to the radiographic guidelines described in literature [15]. The fracture was then fixed with the $2.4 \mathrm{~mm}$ volar locking plate system (Depuy-Synthes, Oberdorf, Switzerland). The distal edge of the plate was carefully positioned proximal to the watershed line to avoid prominence in this area [16]. Multiple fluoroscopic views were checked to avoid intraarticular screw penetration and dorsal screw prominence [17]. The stability of the distal radioulnar joint (DRUJ) was routinely checked and compared with the contralateral side. Cast immobilization, radioulnar pinning, or ulnar styloid ORIF was performed based on the instability of DRUJ according to the established protocol $[18,19]$. Clinical and radiological assessments were performed at 6 weeks, 3 months, 6 months, and 12 months postoperatively according to our routine follow-up regime [19].

We measured four radiological parameters: radial inclination, volar tilt, radial height, and ulnar variance on the Picture Archiving and Communication System (PACS) according as described previously [20]. The fracture re-displacement (FRD), defined as the absolute value of the difference between the postoperative parameters and those taken at the 12-month follow-up. The values were calculated by three different observers, and the final value reported was the mean among the three values reported. Clinical assessment and complications of included patients were recorded during follow-up. 
Patient wrist range of motion (ROMs), pain, and functional outcomes were evaluated according to the Disabilities of the Arm, Shoulder and Hand (DASH) score and the Gartland and Werley score at 12 months postoperatively.

The primary outcome is the maintenance of radiological reduction. The secondary outcome is the reaching of the ROMs recovery (compared with the contralateral side). ROMs on the affected side was calculated in percentage compared with the contralateral side. The fracture healing rate and the presence of complication were also assessed.

SPSS software (SPSS version 18.0, SPSS, IBM Inc., Armonk, NY, USA) was used for all statistical analyses. Data were reported as percentage and frequency for categorical variables. The population normality is checked by $\mathrm{K}-\mathrm{S}$ test and $\mathrm{S}-\mathrm{W}$ test. When the variables obey a normal distribution, they were reported as mean \pm standard deviation (SD). Differences in the radiological parameters between the postoperative values and those taken at the 12-month follow-up were compared using paired-samples $t$ test. FRD was calculated and compared between the intra- and extra-articular distal radius fractures using independent $t$ test. Pearson's chi-squared test was used for nonparametric data. For all statistical tests, $\mathrm{P}<0.05$ was considered statistically significant.

\section{Results}

A total of 173 distal radius fracture patients treca with volar locking plating between Jan 2 16 and Jan 2020 were eligible for inclusion in this stuc All patients were operated within $48 \mathrm{~h}$ from the traum Fort -three patients were excluded because of omplete data settings, open fractures, neurovascular injuryes, or additional ipsilateral upper extremity tures Finally, 130 patients (58 males, 72 females, ve malyded in the study. According to the AC/OTA tem, the patients were classified into A3 (4 ses), C4 (56 cases), or C3 (33 cases) fractures. The mea sngth of follow-up was 17.2 (12-

Table $1 \mathrm{~Pa}$. den ographics in different groups

\begin{tabular}{|c|c|c|c|c|}
\hline & $\begin{array}{l}\text { O/OTA A3 } \\
(n=41)\end{array}$ & $\begin{array}{l}\text { AO/OTA C2 } \\
(n=56)\end{array}$ & $\begin{array}{l}\text { AO/OTA C3 } \\
(n=33)\end{array}$ & $\begin{array}{l}P \\
\text { value }\end{array}$ \\
\hline & $58.5 \pm 12.3$ & $60.2 \pm 11.8$ & $63.1 \pm 12.6$ & $0.487^{a}$ \\
\hline & & & & \\
\hline Female & 22 & 32 & 18 & $0.519^{b}$ \\
\hline Male & 19 & 24 & 15 & \\
\hline \multicolumn{5}{|l|}{ Side } \\
\hline Dominant & 21 & 29 & 19 & $0.144^{b}$ \\
\hline Nondominant & 20 & 27 & 14 & \\
\hline
\end{tabular}

aOne-way ANOVA test.

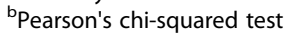

24) months. The demographics of the patients were summarized in Table 1.

Fracture healing was achieved in all patients during follow-up. The union of bone was observed at 6 weeks postoperatively in 97 patients, and at 3 months in the other 33 patients. Three patients had a superficial wound infection postoperatively. The incisio nealed smoothly after dressing changes and antibr ic realment. No serious complication, such as nerve jue $y$, tendon rupture, or implant failure war ecorded a aring follow-up.

The measured radiological par meters we shown in Table 2. No statistically significan change /n volar tilt, radial inclination, radial heigl or a ariance was observed between the immedia postoperative and 12month follow-up meas ments is either of the A3 or the $\mathrm{C} 2$ fracture group. Howe a significant change of the volar tilt was obser $t$ in the $\mathcal{C} 3$ fracture group comparing the immediato ost motive measurements with the 12month follow-up ta $(P=0.037)$. Comparing the FRD calculated the C3 iractures to the A3 ones, a significant decrease of th.e sar tilt was observed in C3 fractures than in A3 $(P=0.003)$ fractures (Table 3$)$. The difference betw the $\mathrm{C} 2$ and A3 fractures, however, did not achieve statis cal significance $(P=0.540)$. Considering the radial $\mathrm{rb}, \mathrm{s}$, the ulnar variance, and the radial inclination, no significant difference of FRD was observed between the intra-articular and the extra-articular fractures (Table 3).

Table 2 Radiological parameters measured in different groups (Mean \pm SD)

\begin{tabular}{|c|c|c|c|}
\hline & Postoperatively & At 12 months & $P$ valuet \\
\hline \multicolumn{4}{|c|}{ AO/OTA A3 fractures } \\
\hline $\mathrm{RI}\left({ }^{\circ}\right)$ & $20.52 \pm 4.08$ & $20.16 \pm 4.14$ & 0.548 \\
\hline $\mathrm{VT}\left({ }^{\circ}\right)$ & $5.06 \pm 3.36$ & $4.83 \pm 3.37$ & 0.455 \\
\hline UV (mm) & $0.19 \pm 0.32$ & $0.22 \pm 0.27$ & 0.231 \\
\hline $\mathrm{RH}(\mathrm{mm})$ & $9.54 \pm 4.18$ & $9.97 \pm 5.08$ & 0.461 \\
\hline \multicolumn{4}{|c|}{ AO/OTA C2 fractures } \\
\hline $\mathrm{RI}\left({ }^{\circ}\right)$ & $19.70 \pm 4.19$ & $19.33 \pm 4.31$ & 0.122 \\
\hline $\mathrm{VT}\left({ }^{\circ}\right)$ & $3.21 \pm 4.46$ & $3.72 \pm 4.04$ & 0.260 \\
\hline UV (mm) & $0.19 \pm 0.29$ & $0.21 \pm 0.33$ & 0.441 \\
\hline $\mathrm{RH}(\mathrm{mm})$ & $9.50 \pm 4.17$ & $9.91 \pm 5.37$ & 0.304 \\
\hline \multicolumn{4}{|c|}{ AO/OTA C3 fractures } \\
\hline $\mathrm{RI}\left({ }^{\circ}\right)$ & $19.24 \pm 4.34$ & $19.73 \pm 4.77$ & 0.302 \\
\hline$V T\left(^{\circ}\right)$ & $3.32 \pm 5.42$ & $2.06 \pm 6.48$ & $0.037^{*}$ \\
\hline UV (mm) & $0.21 \pm 0.37$ & $0.25 \pm 0.40$ & 0.185 \\
\hline $\mathrm{RH}(\mathrm{mm})$ & $9.15 \pm 5.26$ & $9.51 \pm 5.75$ & 0.237 \\
\hline
\end{tabular}

$R H$ radial height, $R I$ radial inclination, $V T$ volar tilt, $U V$ ulnar variance † Paired samples $t$ test

${ }^{*} P<0.05$ 
Table 3 Fracture re-displacement (FRD) calculated in different fracture groups (Mean \pm SD)

\begin{tabular}{llllll}
\hline FRD & A3 & C2 & $P$ valuet & C3 & $P$ value \\
\hline $\mathrm{RI}\left({ }^{\circ}\right)$ & $0.36 \pm 0.41$ & $0.37 \pm 0.39$ & 0.525 & $0.41 \pm 0.33$ & 0.571 \\
$\mathrm{VT}\left(^{\circ}\right)$ & $0.23 \pm 0.16$ & $0.21 \pm 0.61$ & 0.540 & $0.16 \pm 0.90$ & $0.003^{*}$ \\
$\mathrm{UV}(\mathrm{mm})$ & $0.03 \pm 0.32$ & $0.04 \pm 0.27$ & 0.868 & $0.04 \pm 0.31$ & 0.892 \\
$\mathrm{RH}(\mathrm{mm})$ & $0.57 \pm 0.41$ & $0.59 \pm 0.49$ & 0.832 & $0.64 \pm 0.47$ & 0.496 \\
\hline
\end{tabular}

† independent-samples $t$ test, comparison between the $A 3$ and $C 2$ groups \# independent-samples $t$ test, comparison between the $\mathrm{A} 3$ and $\mathrm{C} 3$ groups $* P<0.05$.

At 12 months postoperatively, the mean ROMs of the wrist were shown in Table 4. All of the patients achieved more than $75 \%$ recovery of extension/flexion and more than $95 \%$ recovery of pronation/supination in the injured wrist compared to the contralateral normal wrist. All of the patients achieved adequate functional ROMs according to Ryu's standard [21]. Considering the pronation/supination ROM, no significant difference was observed between the intra-articular (either $\mathrm{C} 2$ or C3) fractures and the extra-articular (A3) fractures. However, the C3 fracture group presented significantly decreased extension/flexion ROMs compared with the A3 fracture group. The mean DASH score was $9.8(0-40)$ at 12 months follow-up. Most patients in our study achi-ved an excellent $(n=75)$ or $\operatorname{good}(n=51)$ Gartla 2 ar $d$
Werley wrist score. Four patients with C3 fractures resulted in a fair functional outcome due to a significant loss of volar tilt during follow-up (Figs. 1, 2, 3 and 4).

\section{Discussion}

Whether the single volar locking plate fixation could provide sufficient stability in the intraarticular astal radius fractures with DMC was not elaborate n iter ture. Previously, biomechanical studies using xtraarticular fracture models have confirm that the ingle volar locking plating could provid an quiv ient or slightly less stability compared wi h dorsal p ang in distal radius fractures with DMC $4,10,11$. In clinical studies, Guillou reported pa. to with a dorsally comminuted extra-articarar a l radius fracture fixed with volar locking pla Most $5.4 \%$ ) of the patients maintained the stabirity h out secondary displacement at 6 months pooc, ratively 22]. Considering the intraarticular frac s $5 \mathrm{MC}$, no straightforward biomechanical stud could be found in literature. In clinical stud Kham, isy compared the outcome of volar locking platirg , the dorsally comminuted (DC) and the dorsally intact (DI) distal radius fractures [23]. The vast mic ity of the cases included in Khamaisy's study were $\mathrm{AO} / \mathrm{CA}$ type $\mathrm{C}$ fractures, and a satisfied fracture retion was preserved in the DC fractures compared to the DI ones with no significant difference observed in (Mean \pm SD)

\begin{tabular}{|c|c|c|c|c|}
\hline Variables & Side & Contralateral Side & $\begin{array}{l}\text { \% of } \\
\text { contralateral wrist }\end{array}$ & $P$ valuet \\
\hline \multicolumn{5}{|c|}{ AO/OTA A3 fractures $\left({ }^{\circ}\right)$} \\
\hline Extension & .71 & $89.22 \pm 9.90$ & 91.7 & \\
\hline Flexion & \pm 9.79 & $88.78 \pm 9.65$ & 91.2 & \\
\hline Pron & $82.20 \pm 7.32$ & $83.46 \pm 6.93$ & 98.4 & \\
\hline Sup & $82.37 \pm 5.48$ & $83.51 \pm 5.56$ & 98.7 & \\
\hline & $75.48 \pm 11.40$ & $89.39 \pm 9.51$ & 84.4 & 0.095 \\
\hline & $73.41 \pm 10.20$ & $88.34 \pm 9.36$ & 83.1 & 0.179 \\
\hline & $81.03 \pm 6.44$ & $83.23 \pm 7.22$ & 97.3 & 0.560 \\
\hline Supination & $81.56 \pm 5.27$ & $83.97 \pm 6.13$ & 97.1 & 0.567 \\
\hline \multicolumn{5}{|c|}{ AO/OTA C 3 fractures $\left({ }^{\circ}\right)$} \\
\hline Extension & $72.51 \pm 17.39$ & $88.36 \pm 7.51$ & 79.8 & $0.044^{*}$ \\
\hline Flexion & $69.57 \pm 19.89$ & $88.97 \pm 7.35$ & 78.2 & $0.035^{*}$ \\
\hline Pronation & $79.84 \pm 8.75$ & $82.49 \pm 6.56$ & 96.7 & 0.311 \\
\hline Supination & $80.69 \pm 5.96$ & $83.18 \pm 5.64$ & 96.9 & 0.560 \\
\hline
\end{tabular}

† Pearson's chi-squared test, compared with the $\mathrm{A} 3$ fracture group

${ }^{*} P<0.05$ 


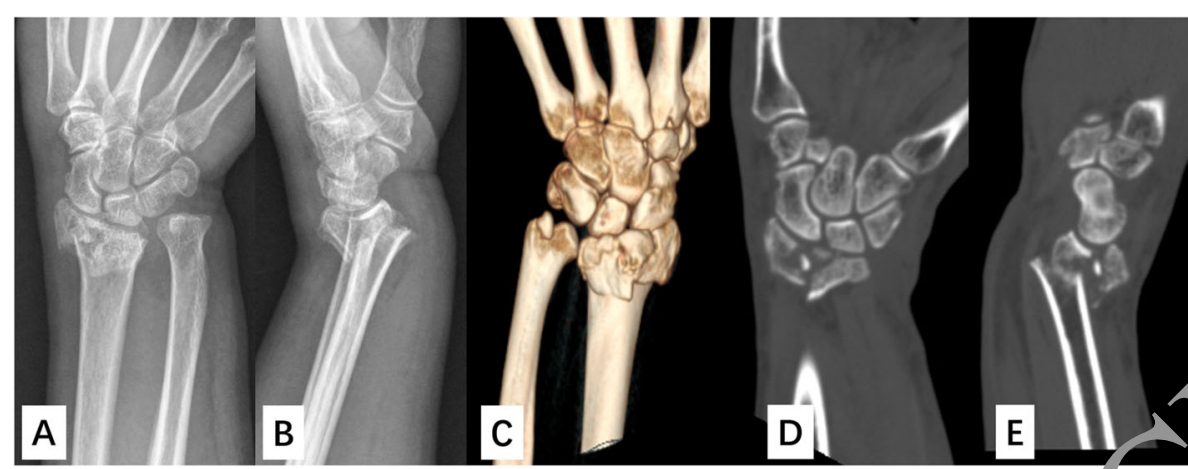

Fig. 1 Case 1. A 69-year-old woman presented with an AO/OTA C3 distal radius fracture with dorsal metaphyseal comm (tion. A, B) Preoperative anteroposterior and lateral view radiographs. C, Three-dimensional computed tomographic image shows the dorsal neta Two-dimensional computed tomographic images confirm the multi-fragmentary articular components

radial inclination, volar tilt, and radial length. These results implied that volar locking plating could provide sufficient stability for the intra-articular fractures despite of the occurrence of DMC. However, the authors didn't compare the outcome among different sub-types of intra-articular fractures due to limited sample size.

In this study, we analyzed the efficacy of volar locking plating in the distal radius fractures with DMC. Compared with the A3 fractures, no significant fracture redisplacement or reduced wrist ROMs was observe $\mathrm{m}$ the intra-articular distal radius fractures with a articular component ( $\mathrm{C} 2$ fractures). However a sig. cant decrease of the volar tilt as well as the tension flexion ROMs were observed in the intr-articu fractures with multi-fragmentary articul o componets (C3 fracture) during follow-up.

For extra-articular fractures with $\mathrm{L} C$ observed similar radiological results Con with Guillou's report [22], wherein no significant ra dic, oraphic change in volar tilt, radial incliat h, radial height, or ulnar variance was found in the 3 fracture group during the 12 months' follow our indings provided extra clinical evidence th molication of volar locking fixation in the extra-artic $r$ distal radius fractures with DMC.

For int rticula fractures with DMC, volar locking plating wast/sc ed to preserve fracture reduction in the C2 fractures, but not in the C3 fractures in this study. O. esults were in contrast to Chou's study, wherein 41 vatie $s$ with AO/OTA C3 dorsally comminuted distal $\mathrm{lia}$ fractures were treated using either dorsal $(\mathrm{n}=22)$ or volar $(n=19)$ locking plate [17]. In both groups, no significant re-displacement was observed in terms of radial inclination, volar tilt, and ulnar variance. Compared with Chou's study, a larger number of cases were included in our study, and the significant loss of volar tilt in the C3 fractures in our study was possibly caused by a compromised subchondral support of the thin and displaced dorsal fragment provided by the distal row of screws with inadequate length (Fig. 3) [24-26]. The subsequent loss of fracture reduction was also observed by

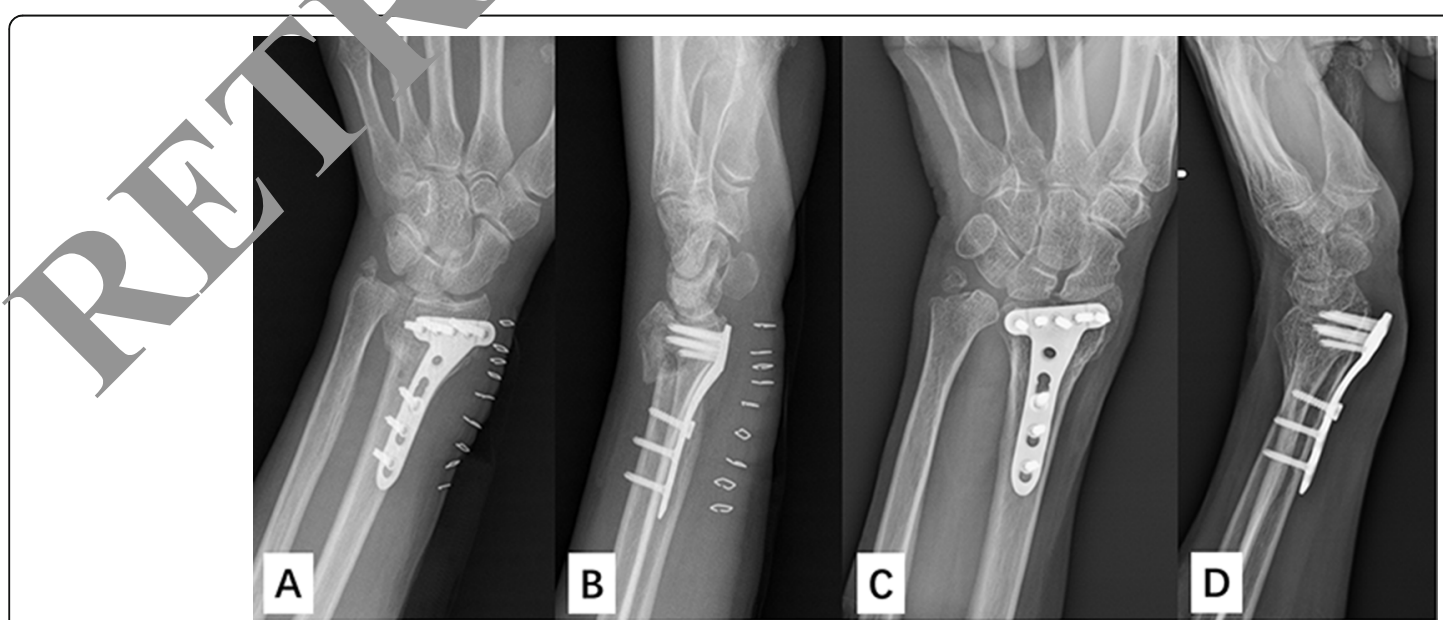

Fig. 2 Case 1. Significant loss of volar tilt was observed at 12-months' follow-up. A, B: Postoperative posteroanterior and lateral radiographs. C, D: Posteroanterior and lateral radiographs at 12-months' follow-up 


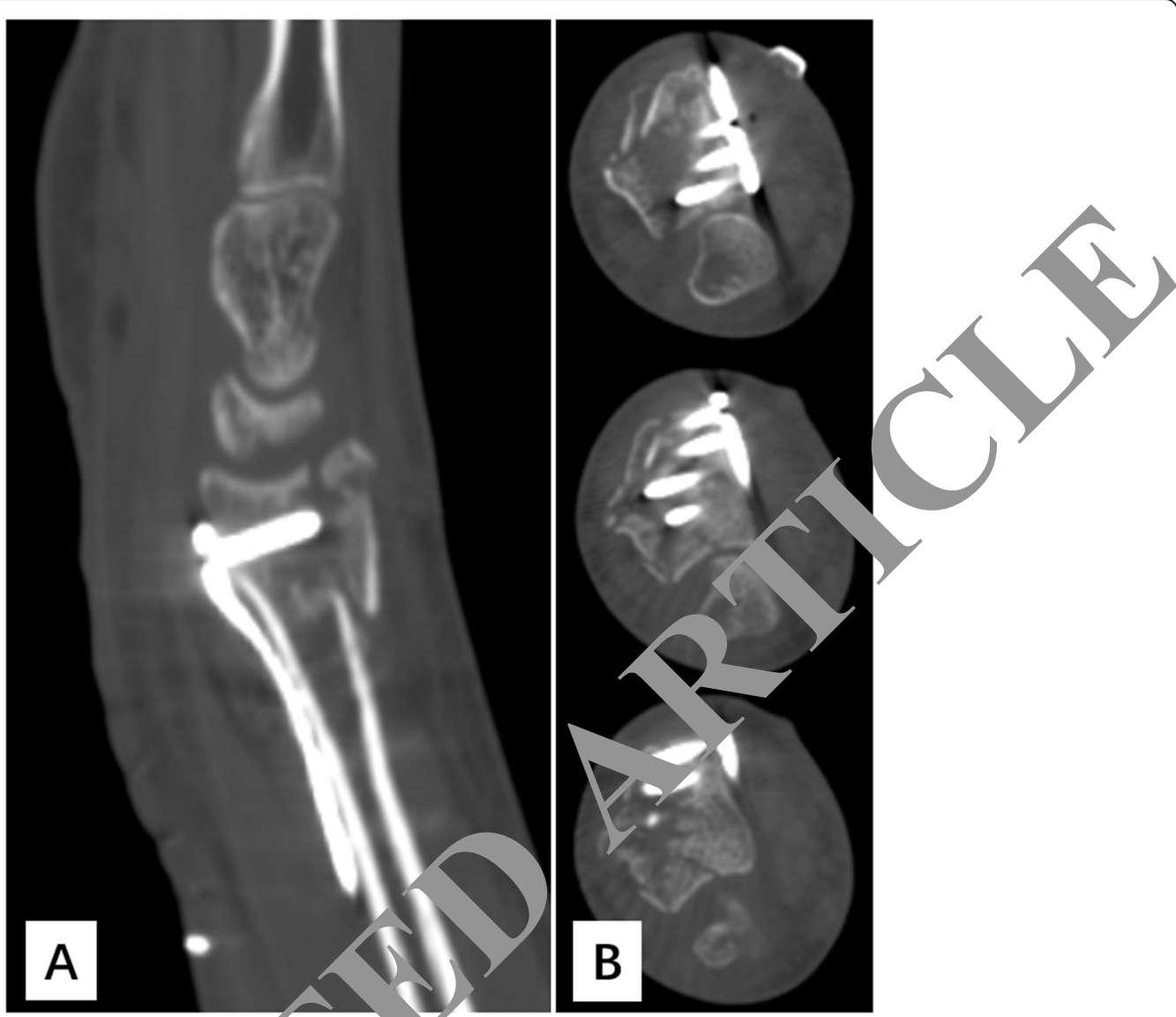

Fig. 3 Case 1. Postoperative computed tomographic no confirme, an inadequate support of the thin and displaced dorsal fracture provided by the distal row of locking screws. A, Sagittal view onthe nage. B, Cross-sectional CT images

Gogna's study, wherein 33 dorsally omminıted distal radius fractures were fixed with volai king plate and followed for over a year [17, 22 기 Totally three cases of C3 fractures (18.7\%) were repertea $\int$ present a dorsal subluxation of the carpus $r$ a loss of dorsal tilt after one-year follow-up. $\pi$ e comparable with our study, and carea for tention to the usage of volar locking plate i C3 froctures with DMC, especially for the fract res wit. he occurrence of radiocarpal fracture disl $r$ ation or dozsal rim fractures [28].

To pre the loss of reduction in C3 fractures, differe - lutic were reported in literature. An appropria len of the distal row of locking screws was proven cruc for the single volar plating construct [26]. However, $y$ e risk of extensor tendon irritation would increase with longer distal radius screws [29]. Multi-row of volar locking screws was considered more stable than the single row screw construct. However, little evidence was provided to support the use of two rows of distal screws over one row in the fixation of distal radius fractures [29]. Besides, the combined usage of volar and dorsal plating was recommended to provide extra buttress for the dorsal fragment $[4,30,31]$.
Dorsal plating was considered as another fixation option to treat distal radial fractures with DMC. Cadaveric reports showed that dorsal plating provided better support than volar plating, and served as a buttress against dorsal comminution [32]. Similar results were confirmed in a dorsally-comminuted sawbone model, in which dorsal pi-plate fixation presented better resistance to fracture gap motion than four different types of volar plate fixation [11]. In clinical studies investigating AO type C3 distal radial fractures, radiological analysis showed a significant difference in comparison with the contralateral side in terms of volar tilt for patients treated with volar plating, whereas there were no significant differences in patients receiving dorsal plating [33]. However, our study found no significant redisplacement in the A3 or $\mathrm{C} 2$ fractures when comparing postoperative and 12month follow-up measurements, indicating that volar locking plates provided sufficient stability in the intraarticular distal radius fractures with a simple articular component.

With regard to the recovery of wrist function, Chou reported a progressive improvement of wrist range of motion following volar plating of C3 dorsally 


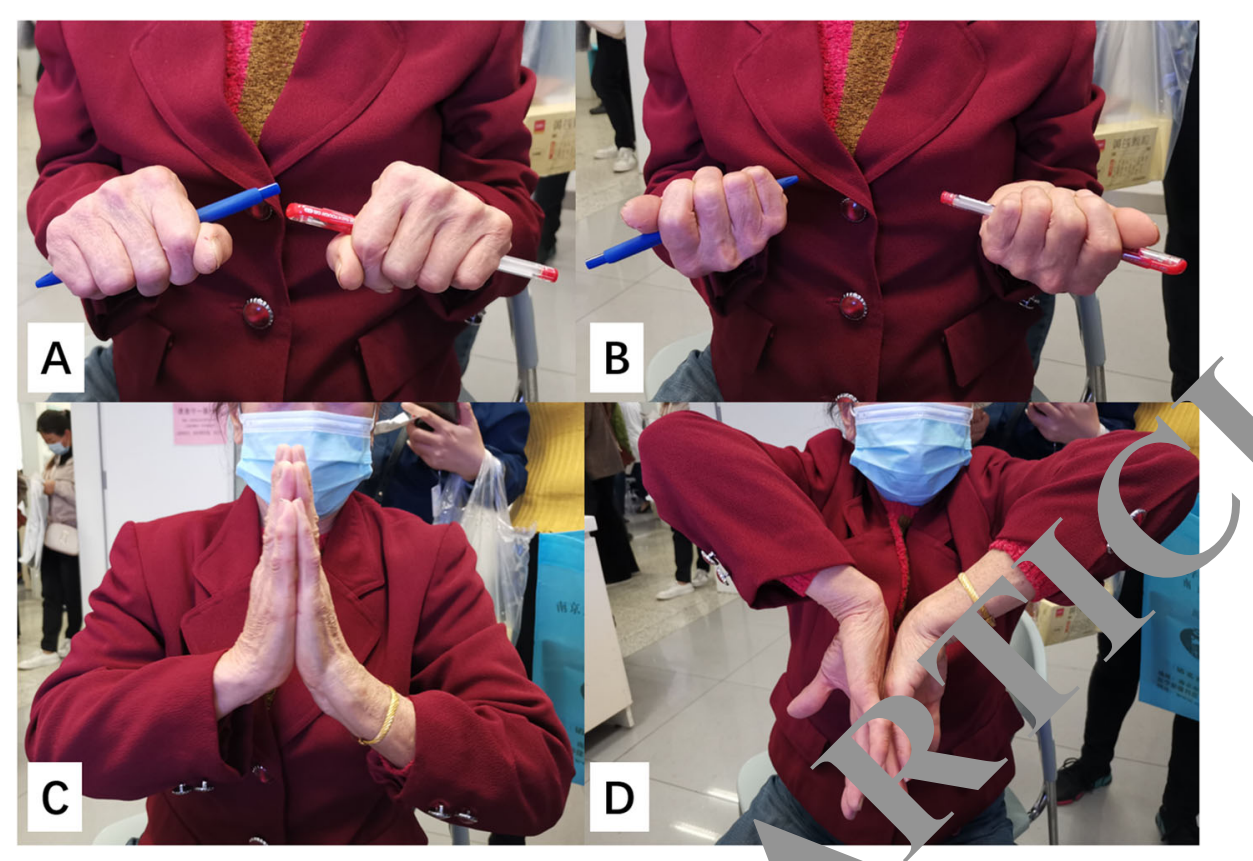

Fig. 4 Case 1. Wrist range of motion at 12-months' follow-up. A, B: A 95\% recovery of pron w supination was achieved in the injured wrist. C, D: A $78 \%$ recovery of extension/flexion was achieved in the injured wrist

comminuted distal radius fractures [17]. After one-year follow-up, the patients showed an $89 \%$ recover of flexion-extension and a $97 \%$ recovery of supi iol pronation compared with that of the contrala a healthy wrists. Compared with Chou's study, patien, with C3 fractures achieved comparable recu ry of supination-pronation range of motion in our stud/. The relatively lower percentage of flexion xtensio' recovery in our study was possibly associated ith the loss of volar tilt in radiological findin $\Gamma_{\mathrm{v}}$ en so, the majority (87.9\%) of the patients with C3 fiacur, s achieved an excellent or good Gartlara d W rley wrist score. Four patients (3.1\%) with ig loss of volar tilt resulted in decreased flex -extension range of motion and a fair func io loutco,ne (Fig. 4). This was consistent with Gr'ta and rugia's findings that volar tilt was one of th most important radiographic parameters affecting th neti nal outcome of distal radius fractures [34,

her no several limitations to our study. First, the stua, vas based on retrospective data, which could harbor co, ifounding sources of bias. Second, the length of the follow-up in our study was reported to be sufficient for the conclusion of radiological and functional outcome, but relatively short for the record of long-term complications [36].

In conclusion, the volar locking plate fixation provided sufficient stability for distal radius fractures with DMC, and resulted in similar radiological and functional outcomes in all of the $\mathrm{C} 2$ fractures as those in the extra- artic ar fractures. Considering the C3 fractures, despite the subsequent loss of volar tilt, the majority of the parients achieved good to excellent wrist function following volar locking plating. Attention should be paid to the $\mathrm{C} 3$ fractures with thin and displaced dorsal fragment, for which the dorsal plating might be an option.

\section{Abbreviations}

DMC: Dorsal metaphyseal comminution; AAOS: American Association of Orthopaedic Surgeons; FCR: Flexor carpi radialis, DRUJ: distal radioulnar joint; ORIF: Open reduction and internal fixation; FRD: The fracture re-

displacement; ROM: Range of motion; DASH: Disabilities of the Arm, Shoulder and Hand score; SPSS: Statistical Product and Service Solutions; DC: The dorsally comminuted distal radius fracture; DI: The dorsally intact distal radius fracture

\section{Acknowledgements}

Not applicable.

\section{Authors' contributions}

Hong-fei SHI and Yi-xin CHEN researched literature and conceived the study. All authors were involved in protocol development. Jin XIONG and Jun-fei WANG were involved in patient recruitment. Xu-sheng QIU and Zi-tao ZHANG were involved in data analysis. Xue-yang GUI and Zhao-hui CHENG wrote the first draft of the manuscript. All authors reviewed and edited the manuscript and approved the final version of the manuscript.

\section{Funding}

This study was funded by the National Natural Science Foundation of China (81401793 and 81572132), the Six Talent Peeks Project in Jiangsu Province (2016-WSW-060), and the Key Project supported by Medical Science and technology development Foundation, Nanjing Department of Health (YKK20086, QRX17007).

\section{Availability of data and materials}

The datasets generated and/or analysed during the current study are not publicly available due to the regulations of IRB, but can be made available from the corresponding author on reasonable request. 


\section{Declarations}

\section{Ethics approval and consent to participate}

This study was conducted in accordance with the Declaration of Helsinki and with approval from the institutional review board (IRB) of Nanjing Drum Tower Hospital. Written informed consent was obtained from all participants.

\section{Consent for publication}

Not applicable.

\section{Competing interests}

The authors declare that they have no competing interests.

\section{Author details}

'Department of Orthopedics, Nanjing Drum Tower Hospital, The Affiliated Hospital of Nanjing University Medical School, No. 321 Zhongshan Road, Nanjing, China. ${ }^{2}$ Nanjing Drum Tower Hospital Clinical College of Nanjing Medical University, Nanjing, China.

\section{Received: 26 May 2021 Accepted: 28 July 2021}

\section{Published online: 25 August 2021}

\section{References}

1. Kennedy SA, Hanel DP. Complex distal radius fractures. J Orthopedic Clinics. 2013;44(1):81-92.

2. Passiatore M, De Vitis R, Perna A, D'Orio M, Cilli V Taccardo G. Extraphyseal distal radius fracture in children: is the cast always needed? A retrospective analysis comparing Epibloc system and K-wire pinning. Eur I Orthop Surg Traumatol. 2020;30(7):1243-50. https://doi.org/10.1007/s00590-020-02698-z.

3. Maccagnano G, Noia G, Vicenti G, Baglioni M, Masciale MR, Cassano GD, et al. Volar locking plate versus external fixation in distal radius fractures: A metaanalysis. Orthop Rev. 2021;13(1):9147. https://doi.org/10.4081/or.2021.9147.

4. Disseldorp DJ, Hannemann PF, Poeze M, Brink PR. Dorsal or Volar Plate Fixa tion of the Distal Radius: Does the Complication Rate Help Us to Choose? J Wrist Surg. 2016:5(3):202-10. https://doi.org/10.1055/s-0036-1571842.

5. Asadollahi S, Keith PP. Flexor tendon injuries following plate fix distal radius fractures: a systematic review of the literature. rthop Traumatol. 2013;14(4):227-34. https://doi.org/10.1007/s10 95- 0245-z. )

6. Makhni EC, Taghinia A, Ewald T, Zurakowski D, Day CS Commin of the dorsal metaphysis and its effects on the radiograp ic outcomes of stal radius fractures. J Hand Surg Eur Vol. 2010;35(8): 2 2-8. https://doi.org/10.11 77/1753193409338750

7. Chuang PY, Yang TY, Shen SH, Tsai YH, Huang KC. Effee ts of Dorsal Cortical Comminution on Radiographic ults following Percutaneous Pinning for Extra-Articular Colles' Fracture Diu 'Dos Int. 2015;2015: 714351

8. Mackenney PJ, McQueen MM, Em R. Prealction of instability in distal radial

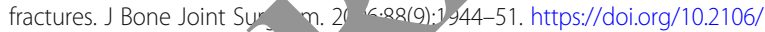
JBJS.D.02520.

9. Wadsten MA, Sayer voor AS, El nd E, Buttazzoni GG, Sjoden GO. Cortical comminution in dis dial fracty,es can predict the radiological outcome: a cohort multicentre s, Bone Joint J. 2014;96-b (7):978-83.

10. Kandemir O, Matityahu \& Jesai R, Puttlitz C. Does a volar locking plate provid qui zlent stability as a dorsal nonlocking plate in a dorsally commin distal dius fracture?: a biomechanical study. J Orthop na. 20 vo:.605-10. https://doi.org/10.1097/BOT.0b013e3181 860

sumi K, Zobitz ME, Cooney WP 3rd. Internal fixation of dorsally aced fractures of the distal part of the radius. A biomechanical analysis of ar plate fracture stability. J Bone Joint Surg Am. 2006;88(11):2411-7. httrs://doi.org/10.2106/00004623-200611000-00013.

12. Wadsten MA, Sayed-Noor AS, Sjoden GO, Svensson O, Buttazzoni GG. The Buttazzoni classification of distal radial fractures in adults: interobserver and intraobserver reliability. Hand (New York, NY). 2009:4(3):283-8.

13. Marsh JL, Slongo TF, Agel J, Broderick JS, Creevey W, DeCoster TA, et al. Fracture and dislocation classification compendium - 2007: Orthopaedic Trauma Association classification, database and outcomes committee. J Orthop Trauma. 2007;21(10 Suppl):S1-S133. https://doi.org/10.1097/ 00005131-200711101-00001.

14. Gui XY, Shi HF, Xiong J Chen YX Wang JF, Huang J et al. A modified intrafocal pinning technique with three-dimensional planning to facilitate volar plating in dorsally comminuted AO/OTA C2 and C3 distal radius fractures. BMC Musculoskelet Disord. 2021;22(1):379. https://doi.org/10.1186/ s12891-021-04265-x.

15. Nana AD, Joshi A, Lichtman DM. Plating of the distal radius. J Am Acad Orthop Surg. 2005;13(3):159-71. https://doi.org/10.5435/00124635-2 00505000-00003.

16. Soong M, Earp BE, Bishop G, Leung A, Blazar P. Volar locking plate implant prominence and flexor tendon rupture. J Bone Joint Surg Am. 2011:93(4): 328-35. https://doi.org/10.2106/JBJS.J.00193.

17. Chou YC, Chen AC, Chen CY, Hsu YH, Wu CC. Dorsal and vo 4-r n titanium locking plate fixation for $\mathrm{AO}$ type $\mathrm{C} 3$ dorsally commin radius fractures. J Hand Surg. 2011;36(6):974-81. https//doi.org/10 jhsa.2011.02.024

18. Sammer DM, Chung KC. Management of the divtal ra nar joj $r$ and ulnar styloid fracture. Hand Clin. 2012;28(2):399-206. http. Jorg/10.1016/ j.hcl.2012.03.011.

19. Chen $Y X$, Zheng $X$, Shi HF, Wangyang YF, an $H$, Xie $\rangle X$, et al. Will the untreated ulnar styloid fracture inf ce th the of unstable distal radial fracture treated with exte nal th $n$ when the distal radioulnar joint is stable. BMC Musculoskelet isord. 201. 17):186. https://doi.org/10.11 86/1471-2474-14-186.

20. Kreder HJ, Hanel DP, Mckee M, ter J, McGillivary G, Swiontkowski MF. Xray film measurem for healed al radius fractures. J Hand Surg. 1996; 21(1):31-9. http //doi.t y/10.1016/50363-5023(96)80151-1.

21. Ryu JY, Cooney $30 \quad \measuredangle J$, An KN, Chao EY. Functional ranges of motion of the wris t. J Hand Surg. 1991;16(3):409-19. https://doi.org/1 $0.1016 / 23-5023(91)$ > J6-W.

22. Guillou J, Bougès C, Christiaens N, Guerre E, Chantelot C. What happens to the pjsterior comminution in extra-articular fractures of the distal radiu treated with volar locking plates? Hand Surg Rehabil. 2019; Q(2):91-6. hittps://doi.org/10.1016/j.hansur.2018.10.238.

23. maisy $S$, Weil $Y A$, Safran $O$, Liebergall M, Mosheiff $R$, Khoury A. Outcome of do ally comminuted versus intact distal radial fracture fixed with volar locking tes. Injury. 2011;42(4):393-6. https://doi.org/10.1016/j.injury.2010.10.011. igl M, Weninger P, Jurkowitsch J, Hofbauer M, Schauer J, Leixnering M. Unstable distal radius fractures in the elderly patient--volar fixed-angle plate osteosynthesis prevents secondary loss of reduction. J Trauma. 2010;68(4): 992-8. https://doi.org/10.1097/TA.0b013e3181 b99f71.

25. Rhee SH, Kim J, Lee YH, Gong HS, Lee HJ, Baek GH. Factors affecting late displacement following volar locking plate fixation for distal radial fractures in elderly female patients. Bone Joint J. 2013;95-b(3):396-400.

26. Wall LB, Brodt MD, Silva MJ, Boyer MI, Calfee RP. The effects of screw length on stability of simulated osteoporotic distal radius fractures fixed with volar locking plates. J Hand Surg. 2012;37(3):446-53. https://doi.org/10.1016/j. jhsa.2011.12.013

27. Gogna P, Selhi HS, Singla R, Devgan A, Magu NK, Mahindra P, et al. Dorsally comminuted fractures of the distal end of the radius: osteosynthesis with volar fixed angle locking plates. ISRN Orthopedics. 2013;2013:131757.

28. Garg R, Mudgal CS. When a volar locking plate is not the right choice in fractures of the distal radius: Case based technical considerations. J Clin Orthop Trauma. 2020;1 (4):542-53. https://doi.org/10.1016/j.jcot.2020.05.040.

29. Ramavath A, Howard N, Lipscombe S. Biomechanical considerations for strategies to improve outcomes following volar plating of distal radius fractures. J Orthop. 2019;16(5):445-50. https://doi.org/10.1016/j.jor.2019.04.006.

30. Day CS, Kamath AF, Makhni E, Jean-Gilles J, Zurakowski D. "Sandwich" plating for intra-articular distal radius fractures with volar and dorsal metaphyseal comminution. Hand (New York, NY). 2008;3(1):47-54.

31. Farhan MF, Wong JH, Sreedharan S, Yong FC, Teoh LC. Combined volar and dorsal plating for complex comminuted distal radial fractures. J Orthop Surg (Hong Kong). 2015;23(1):19-23. https://doi.org/10.1177/230949901502300105.

32. Blythe $M$, Stoffel $K$, Jarrett $P$, Kuster M. Volar versus dorsal locking plates with and without radial styloid locking plates for the fixation of dorsally comminuted distal radius fractures: a biomechanical study in cadavers. Hand Surg. 2006;31(10):1587-93. https://doi.org/10.1016/j.jhsa.2006.09. 011.

33. Rein S, Schikore H, Schneiders W, Amlang M, Zwipp H. Results of dorsal or volar plate fixation of $\mathrm{AO}$ type $\mathrm{C} 3$ distal radius fractures: a retrospective study. J Hand Surg. 2007;32(7):954-61.

34. Batra S, Gupta A. The effect of fracture-related factors on the functional outcome at 1 year in distal radius fractures. Injury. 2002;33(6):499-502. https://doi.org/10.1016/S0020-1383(01)00174-7. 
35. Perugia D, Guzzini M, Civitenga C, Guidi M, Dominedò C, Fontana D, et al. Is it really necessary to restore radial anatomic parameters after distal radius fractures? Injury. 2014;45(Suppl 6):S21-6. https://doi.org/10.1016/j.injury.2 014.10.018.

36. Hattori Y, Doi K, Sakamoto S, Yukata K. Delayed rupture of extensor digitorum communis tendon following volar plating of distal radius fracture. Hand Surgery. 2008;13(3):183-5.

\section{Publisher's Note}

Springer Nature remains neutral with regard to jurisdictional claims in published maps and institutional affiliations.

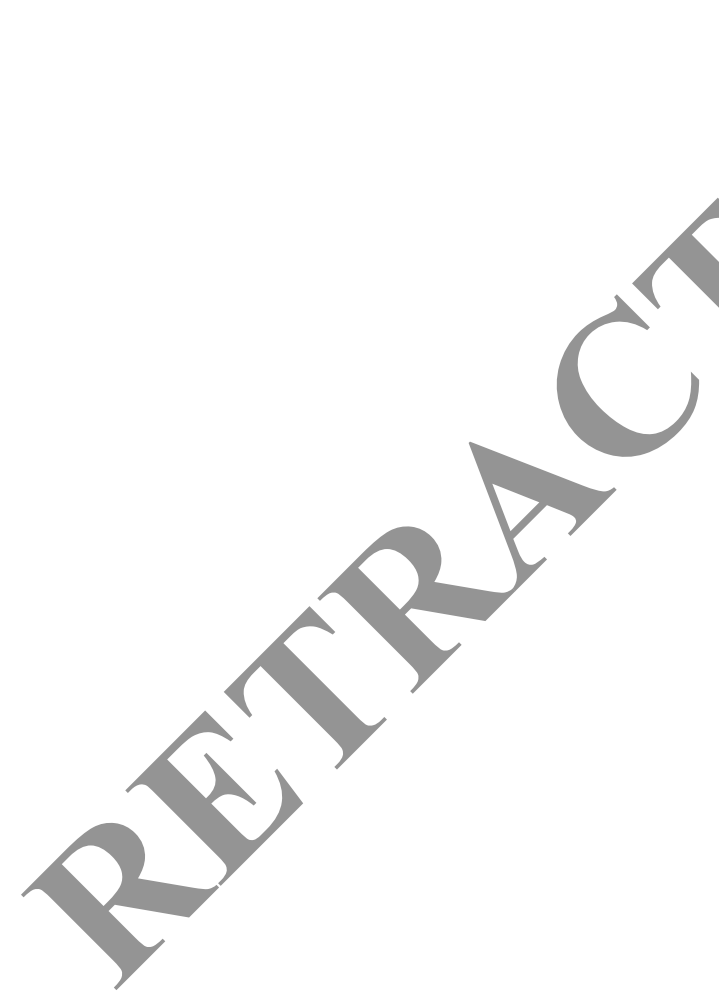

Ready to submit your research? Choose BMC and benefit from:

- fast, convenient online submission

- thorough peer review by experienced researchers in your field

- rapid publication on acceptance

- support for research data, including large and complex data types

- gold Open Access which fosters wider collaboration and increased citations

- maximum visibility for your research: over $100 \mathrm{M}$ website views per year

At $\mathrm{BMC}$, research is always in progress.

Learn more biomedcentral.com/submissions 